\title{
ОСОБЕННОСТИ ЦИФРОВОЙ ТРАНСФОРМАЦИИ БАНКОВСКОЙ ОТРАСЛИ
}

\author{
(C) 2021 Оганнисян Корюн Агванович \\ Студент 4го курса, Факультет «Высшая школа управления» \\ Финансовый университет при Правительстве Российской Федерации, Россия, Москва \\ E-mail: ogannisyan.koryun@yandex.ru
}

\begin{abstract}
Научный руководитель Удальцова Наталья Леонидовна
кандидат экономических наук, доцент департамента Менеджмента и инноваций, Факультет «Высшая школа управления»

Финансовый университет при Правительстве Российской Федерации, Россия, Москва

E-mail: udaltsova.nl@yandex.ru
\end{abstract}

Цифровая трансформация ускоренными темпами распространяется на большую часть отраслей экономики и никак не может не затронуть банковский сектор. Появляется необходимость цифровой трансформации кредитно-финансовых организаций и оптимизация их деятельности под условия сегодняшнего дня.

Ключевые слова: иифровая трансформация, инновации, цифровизация, технологии, банковский сектор, цифровое развитие.

\section{Введение}

В условиях постоянно развивающегося мира цифровая трансформация не может не затронуть банковский сектор. Данная отрасль является неотъемлемым сегментом цифровой экономики. Это обуславливает актуальность рассмотрения технологической составляющей цифровой экономики банковской системы, вместе с этим стоит обратить внимание на перспективы применения технологий, которые используются в процессе цифровой трансформации банковской системы.

Благодаря использованию инновационных технологических продуктов в банковской сфере, интерес клиентов к оказанию услуг в цифровом формате постепенно возрастает. В свою очередь, кредитные организации должны обеспечивать должный уровень сервиса и кибербезопасности, сокращая время на оказание услуг и предоставляя полную защиту данных клиентов.

\section{Основная часть}

На сегодняшний день инвестиции в интеллектуальный капитал в условиях цифровизации экономики являются наиболее сильным рычагом, влияющим на рост эффективности мировой экономики. Другими словами, происходит стимулирование экономического развития практически всех отраслей, возникновение новых рынков, бизнес-направлений, обеспече- ние эффективного функционирования и роста стабильности всей денежно-кредитной системы России. Внедрение технологической составляющей в работу финансового сектора экономики оказало влияние на возникновение такого понятия как «FinTech». Следует отметить, что нововведения в финансовой среде касаются не только взаимодействия между бизнес-субъектами (B2B), но и в деловых отношениях B2C, B2G, а также при оказании банками государственных услуг.

В данный момент времени цифровизация услуг банковской системы продвинулась достаточно далеко. Показатели по цифровизации российского банковского сектора не уступают показателям на международной арене. Чуть менее 90\% банков Российской федерации уже постепенно внедряют программы цифровых трансформаций в свою деятельность, и это является весьма положительной тенденцией [3].

Российский фонд Сколково провел исследование, посвященное кредитным организациям, которые внедрили в свою работу цифровые технологии. Кроме того, по результатам исследования был создан рейтинг банков, которые внедряют в работу инновационные разработки и постоянно совершенствуют действующие бизнес-модели. Среди крупнейших игроков рынка можно выделить Сбер, Тинькофф, Альфа-Банк, Росбанк, ВТБ, Русский стандарт и так далее [8]. 
Банки в процессе развития цифровизации проводят широкую инвестиционную политику. K примеру, объем инвестиций, направляемый банками на развитие программ цифровых трансформаций, составляет более 55 млрд. рублей в год. Что касается вклада Сбера в развитие цифровых технологий, то за четыре года было вложено более 400 млрд. рублей [7].

В 2019 году было проведено исследование, инициатором которого стал ВЦИОМ. На основании этого исследования выяснилось, что банковские операции представляют собой наиболее популярную онлайн-услугу. Это означает, что большинство опрошенных (61\%) проводят банковские транзакции через цифровые каналы. Среди этого большинства 77\% клиентов относятся к возрасту от 18 до 24 лет. Следовательно, развитие цифровых технологий активно поддерживается, в первую очередь, молодым поколением [9].

В течение 2016-2020 гг. наблюдается значительный рост активности населения в вопросах использования цифровых каналов банковских операций. Об этом свидетельствуют статистические данные, на основании которых можно отследить рост клиентов, предпочитающих работать с банками дистанционно. Например, в 2016 году россияне, предпочитающие цифровые каналы обслуживания составляли 19\% от населения страны, в 2018 году данный показатель возрос до $45 \%$, а в 2020 году и вовсе превысил 50\% от общего числа населения Российской Федерации [6].
Рассмотрим основные технологии, которые наиболее популярны среди клиентов банковской системы:

- Искусственный интеллект (всевозможные помощники в приложениях, одобрение кредитов без участия консультантов и так далее);

- Big Data;

- Боты, отвечающие на вопросы в чатах;

- Распознавание по биометрическим данным.

Данные технологии, в силу их популярности, банковские представители планируют развивать в первую очередь (рис. 1).

Технология искусственного интеллекта активно развивается в банковских продуктах. Она помогает решать множество задач, исключая при этом человеческий фактор и экономя время. Искусственный интеллект позволяет подстраивать банковские услуги под желания и ожидания клиентов. Активно развивается с помощью искусственного интеллекта такое направление как персонализация банковских услуг. На основании предпочтений клиента система сможет предложить ему новые услуги и приложения. Важным моментом является обеспечение системы кибербезопасности. Искусственный интеллект позволяет распознать мошеннические действия, а используемый анализ биометрических данных является дополнительной защитой при идентификации клиента системой. К биометрическому анализу относится сканирование отпечатка пальцев и лица, запись и анализ голоса, аутен-

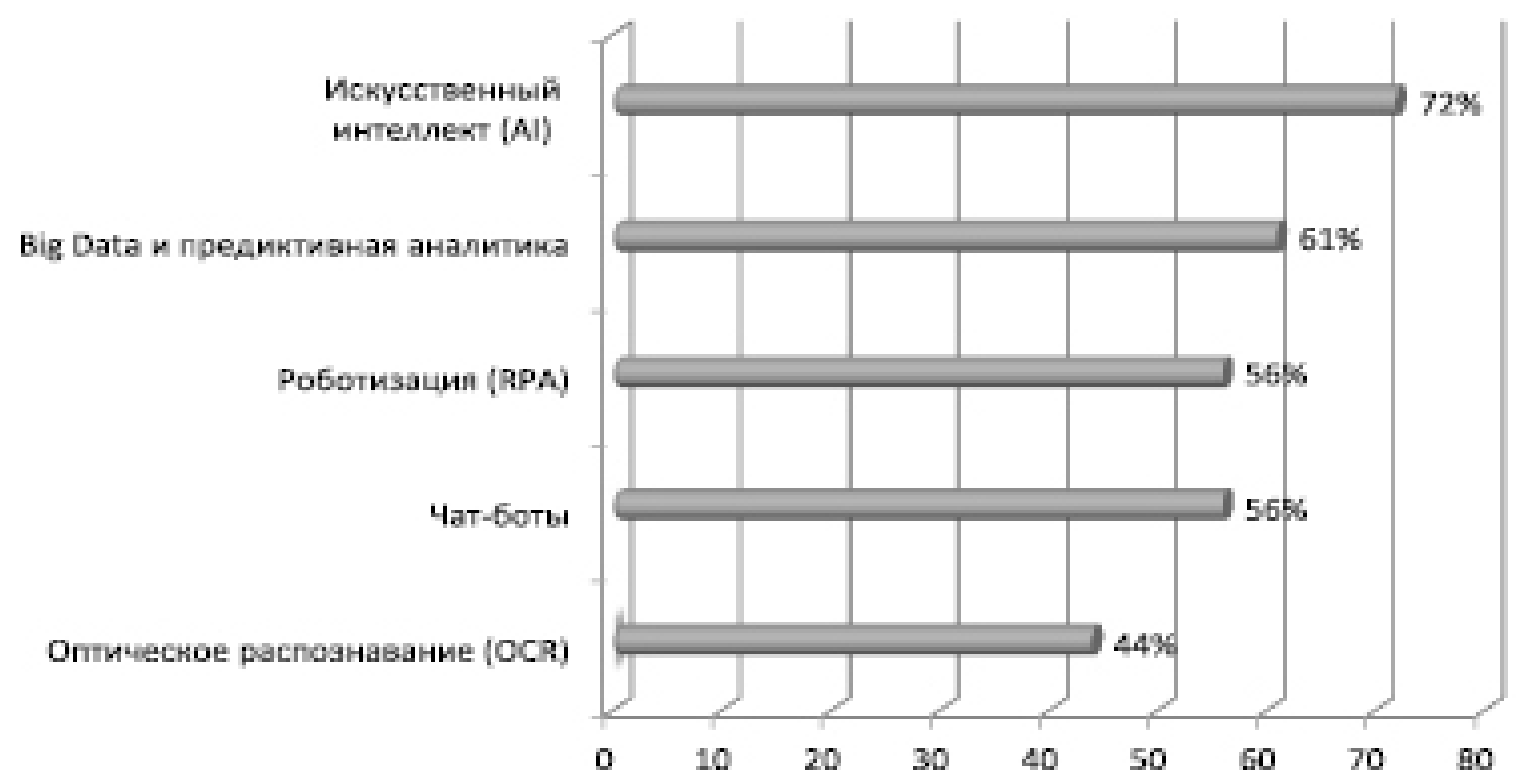

Puc. 1. Основные технологии, которые планируют развивать российские банки в ближайшее время. Источник: КПМГ. Цифровые технологии в российских компаниях [3] 
тификация по рисунку вен на ладони.

Разработка и внедрение биометрической системы относятся к периоду 2017 года. Первый запуск данной системы был произведен летом 2018 года. На начало 2020 года количество клиентов, которые используют биометрическую систему анализа данных составило более 110 тысяч человек [1]. Обработкой информации больших объемов, поступающих из различных источников данных, помогает заниматься система Big Data. Это позволяет анализировать кредитную историю клиента, понимать структуру его расходов, использовать оценку доходности его денежных средств для предложения различных продуктов. Банк, на основании анализа клиента, может предлагать ему кредитные программы, услуги по вкладам, дополнительные преференции и выпуск карточек по эксклюзивным программам. Чтобы работа клиента и банка была наиболее плодотворной и быстрой, было принято решение внедрить в работу банковской системы так называемых чат-ботов. С увеличением популярности мобильных банковских приложений, чат-боты стали неотъемлемой частью данной услуги.

Как правило, обращение клиентов к консультантам происходит по одним и тем же вопросам. Предложить быстрый вариант решения проблемы, согласно отработанному алгоритму, сэкономив при этом значительную часть времени на ожидание ответа консультанта, помогает чат-бот. В настоящее время одним из основных ресурсов является время, поэтому данная услуга набирает популярность среди клиентов банка. Популярность мобильного приложения растет с каждым годом, среди наиболее востребованных продуктов внутри приложения являются: перевод денег по номеру телефона, оплата коммунальных услуг, оплата мобильной связи и интернета, а также оплата различного вида услуг по QR-коду [4]. Усилению развития цифровизации банковских услуг препятствует недостаточная степень готовности клиентов. Не все клиенты могут довериться новым технологиям и быстро их освоить. Кроме того, не все кредитные учреждения готовы внедрять в свою работу новейшие цифровые инструменты и, более того, проводить цифровую трансформацию всей работы организации. Следует отметить, что клиенты иногда не осведомлены о наличии тех или иных услуг, предоставляемых банками. Так, по результатам исследования Аналитического центра НАФИ, был составлен список наименее известных сервисов (рис. 2).

Рассмотрим действующую бизнес-модель ПАО «СберБанк». В центре бизнес-модели Сбербанка находится клиент. Полная ориентация на предпочтения и желания клиентов является основной идеей построения всей экосистемы Сбербанка. Банк использует подход Run Change - Disrupt. Это означает, что развитие этих трех ступеней позволяет Сберу сохранять лидерские позиции на рынке Российской Федерации. Первоочередной задачей является удовлетворение запросов клиентов в финансовой сфере, далее банк располагает продуктами экосистемы,

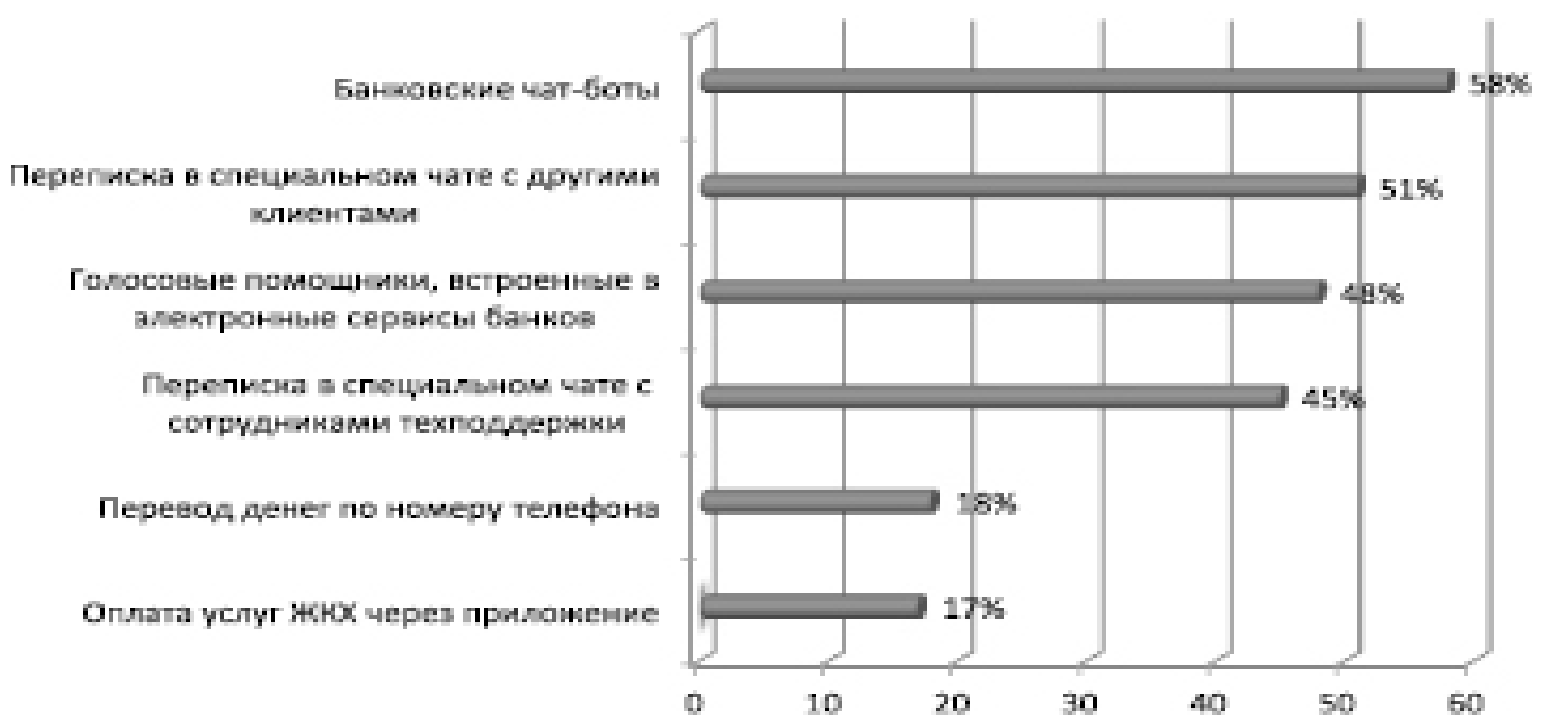

Pис. 2. Цифровые сервисы, о которых не знают участники. 
которые могут закрыть все другие потребности. Цифровая трансформация значительно поменяла суть отношения клиент-банк. Теперь банк выступает не просто в качестве финансовой организации, а как полноценный финансовый институт, осуществляющий свою деятельность на единой цифровой платформе. Сегодня банк не просто проводит финансовые операции, а является цифровым организмом, который взаимодействует со своими клиентами, отталкиваясь от их основных потребностей. В этом случае на фоне разнообразия продуктов экосистемы, финансовые услуги являются лишь небольшой частью всего предоставляемого спектра. На рынке кредитных организаций Российской Федерации идет активная борьба за внимание клиентов. Поэтому, бизнес-направления по развитию будут развиваться с учетом сохранения необходимого уровня лояльности клиентов. В ход вступают новые понятия в развитии бизнес-моделей, такие как эмпатия и дизайн-мышление. Новейшие подходы к реализации услуг предоставят банку возможность, которая будет проявляться в массовой персонализации. Другими словами, клиентоориентированный подход выходит на новый уровень с помощью Big Data. Данная технология на основе сбора и обработки большого объема информации позволяет подбирать каждому клиенту персональные предложения, ко- торые заинтересуют именно его.

Бизнес-модель ПАО «Сбербанк» на сегодняшний день - клиентоцентричная экосистема. Компания уделяет особое внимание текущей деятельности. Грамотное управление, анализ внешней среды, планирование показателей и выстраивание стратегий, а также контроль за выполнением намеченного являются обязательными условиями. Внедряя новые технологии, специалисты обязаны просчитать все варианты развития событий, так как проверка проходит сразу на большой аудитории. Поэтому, проектное управление неотъемлемая часть каждого нового продукта экосистемы Сбера.

В мире развитие технологий происходит с каждым днем все быстрее, от этого растет требовательность клиентов. Для повышения лояльности и сохранения лидерских позиций Сбер обязан постоянно совершенствоваться, именно поэтому, третьей важной ступенью является развитие стартапов и финансирование новых направлений.

Как было отмечено ранее, деятельность Сбер построена на трех основных принципах, развитие которых позволит удерживать конкурентные позиции и расширять границы занимаемого рынка.

Сбербанк подходит с новаторским подходом к процессу корпоративного управления, в связи

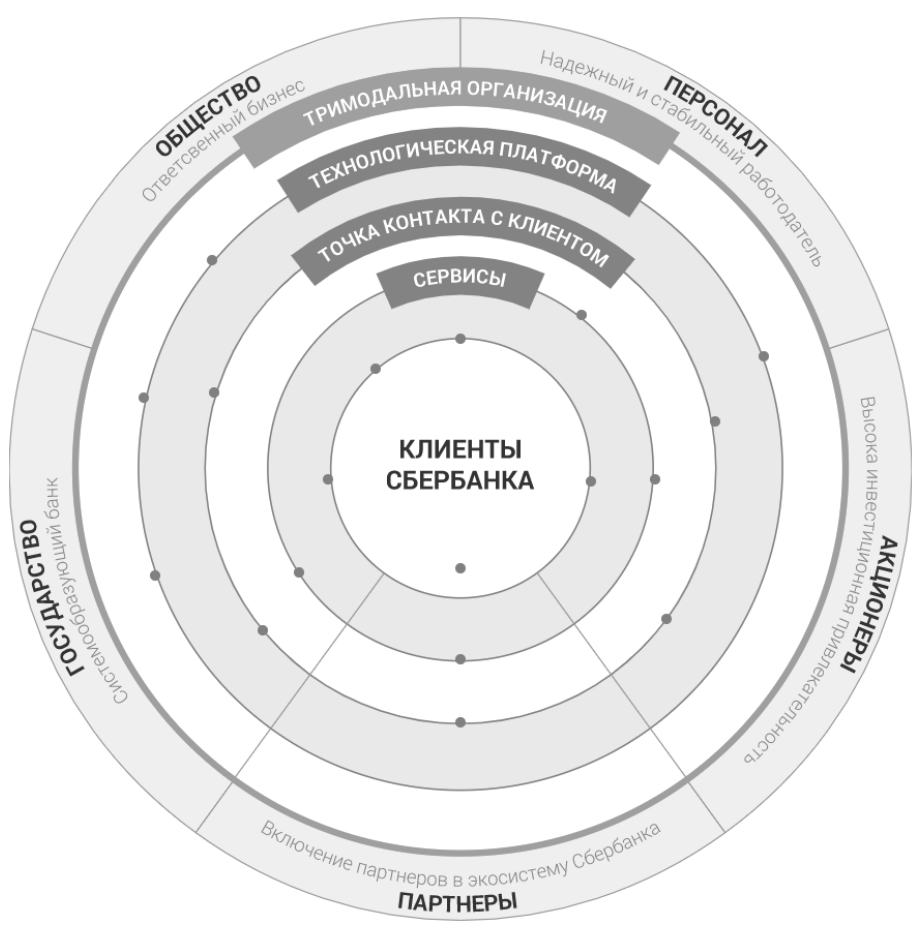

Pис. 3. Бизнес-модель СберБанка. Источник: Бизнес-модель СберБанка [2] 


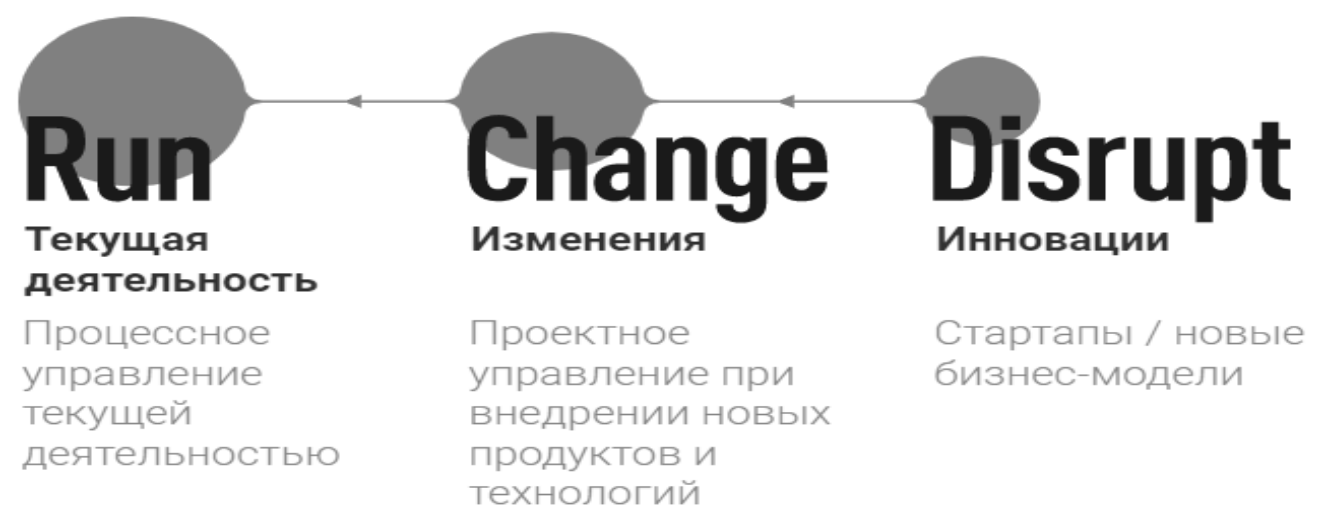

Рис. 4. Тримодальность ПАО «СберБанк» Источник: Тримодальность Сбер [5]

с этим, компания одной из первых начала проводить политику цифровой трансформации в системе управления человеческими ресурсами. Со слов главы Сбера Германа Грефа, система КРI не может применяться в современной компании, которая развивается как с технологической, так и с социальной сторон. Он считает, что система KPI отрицательно сказывается на конечный результат работы персонала, если рассматривать их с позиции клиентоориентированности.

Таким образом, Сбер предложил свою концепцию, которую успешно реализует в корпоративном управлении с 2016 года. Проект носит название «бирюзовой организации» и основан на следующих принципах: самоуправление сотрудников, всестороннее развития персонала для повышения компетентности и профессионализма, работа по принципу доверия, оперативность системы обмена информацией, распределение доходов в коллективе-поровну.

Такой подход позволит повысить интерес сотрудников в плане корпоративного управления, так как общий результат теперь будет зависеть от всех вместе. Сотрудники повышают клиентоориентированность своих действий и несут полную ответственность за все действия. Таким образом, происходит уход от гонки за достижением плановых показателей и выстраиваются настоящие партнерские отношения. Этот принцип сложно применим в современной России, так как, в большинстве своем люди привыкли к подчинению в силу менталитета. Однако, применение данной системе в ПАО «СберБанк» принесло свои результаты и сотрудники постепенно, но перестраиваются на новые принципы работы. На наш взгляд, реализации основных приоритетов «бирюзовой организации» Сбербанка может поспособствовать технология Agile, ак- тивно применяемая на Западе в сфере IT - технологий. При этом Agile- подходы применяются не только в разработке программного обеспечения, но и в производстве физических вещей и даже в госуправлении. Agile представляет собой гибкую методологию разработки и управления проектами. Отличительной чертой стратегии Сбера является то, что большое внимание компания уделяет кибербезопасности. Существующим сервисом «Кибербезопасность» пользуются бизнесмены, проводящие операции через банк. Данная отрасль представлена компанией БИЗон.

Таким образом, рассмотрев основные аспекты действующей стратегии ПАО «СберБанк», следует отметить, что основное ее направление- поддержание действующего лидирующего положения на рынке, путем развития и увеличения доли небанковских сервисов экосистемы. Применение опыта успешных стран и постоянный мониторинг новых потребностей клиентов позволяет компании в кратчайшие сроки реализовывать инновационные идеи и внедрять новые сервисы в экосистему, где каждый пользователь сможет ими воспользоваться, имея свой ID-номер.

\section{Заключение}

Таким образом, благодаря использованию инновационных технологических продуктов в банковской сфере, интерес клиентов к оказанию услуг в цифровом формате постепенно возрастает. В свою очередь, кредитные организации должны обеспечивать должный уровень сервиса и кибербезопасности, сокращая время на оказание услуг и предоставляя полную защиту данных клиентов.

Текущее состояние банковской сферы Российской Федерации находится на высоком уров- 
не и имеет все предпосылки для дальнейшего развития процесса цифровой трансформации кредитных организаций. Между тем, данный уровень технологий, который можно наблюдать на сегодняшний день, дает предпосылки для выхода российской банковской системы в число мировых лидеров по оказанию данного вида цифровых услуг.

\section{Библиографический список}

1. Банки не выполняют план ЦБ по сбору биометрии // Ведомости / [Электронный ресурс]. - Режим доступа: URL: https://www.vedomosti.ru/finance/articles/2020/01/10/820276-plan-tsb-po-biometrii

2. Бизнес-модель СберБанка // [Электронный ресурс] / Сбербанк.-Режим доступа: URL: https://www.sberbank. $\mathrm{ru} / \mathrm{ru} /$ person

3. КПМГ. Цифровые технологии в российских компаниях [Электронный ресурс].- Режим доступа: URL: https://home.kpmg/ru/ru/home/insights/2019/01/digital-technologies-inrussian-companies-survey.html

4. НАФИ назвал самые популярные среди россиян цифровые сервисы банков // Коммерсант / [Электронный peсурс].- Режим доступа: URL: https://www.kommersant.ru/doc/4157220

5. Тримодальность Сбер// [Электронный ресурс] / Сбербанк.- Режим доступа: URL: https:/www.sberbank.ru/ $\mathrm{ru} /$ person

6. Удаленные перспективы // Коммерсантъ / [Электронный ресурс].- Режим доступа: URL: https://www. kommersant.ru/doc/4013343

7. ФИНТЕХ 2019 [Электронный ресурс]. - Режим доступа: URL: https://bloomchain.ru/Fintech2019.pdf

8. Фонд «Сколково» и VR_Bank составили рейтинг цифровизации банков [Электронный ресурс].- Режим доступа: URL: https://sk.ru/news/b/pressreleases/archive/2019/08/21/fond-skolkovo-i-vr-bank-sostavilireytingcifrovizacii-bankov.aspx

9. Цифровизация услуг в России: уже на пороге / ВЦИОМ/ [Электронный ресурс].- Режим доступа: URL: https://wciom.ru/index.php?id=236\&uid=9667 \&fbclid=IwAR0cofbx0-1CLS-dBS1RqJfOgHPCR39P8q68UyuEAI0z 74JaiyIU1OIfyM 